\title{
A Comprehensive Study on Availability of Anti-cancer Drugs in Dhaka City, Bangladesh
}

\author{
Rumman Reza' ${ }^{1}$, Md. Nazmus Samdani ${ }^{1}$, Niaz Morshed ${ }^{1}$ and Nusrat Ahmed ${ }^{2}$ \\ ${ }^{1}$ Department of Pharmacy, Faculty of Pharmacy, University of Dhaka, Dhaka-1000, Bangladesh \\ ${ }^{2}$ Department of Pharmaceutical Technology, Faculty of Pharmacy, University of Dhaka \\ Dhaka-1000, Bangladesh
}

(Received: June 22, 2020; Accepted: July 17, 2020; Published (web): July 25, 2020)

\begin{abstract}
With the increasing rate of people being affected by cancer in Bangladesh, the disease has become a national concern. Anti-cancer drugs play a significant and crucial role in cancer treatment regimen. Inadequate access to essential anti-cancer medicines may impose serious public health problems in Bangladesh. The present study gives an insight on the availability of eleven WHO enlisted essential anticancer drugs that are commonly prescribed for the top five prevalent cancer types (Breast, Oesophagus, Lung, Cervix, Lips and Oral cavity) in Bangladesh. Expert advice on which essential anti-cancer medicines are commonly prescribed were gathered from oncologists of three medical college hospitals (Dhaka Medical College Hospital (DMCH), Bangabandhu Sheikh Mujib Medical University (BSMMU) and National Institute of Cancer Research and Hospital (NICRH). The study was conducted among a total of 151 pharmaceutical drug stores including 119 retail, 27 model and 5 hospital pharmacies. The sample size of 151 pharmacies was calculated for 4547 pharmacies in Dhaka district with $95 \%$ confidence interval and $8 \%$ margin of error. It was found that $74 \%$ of the pharmacy stores surveyed kept no anti-cancer drugs at all. There is a significant negative relationship between price and availability of oncology medicine for which Pearson's correlation co-efficient ' $r$ ' is found to be -0.739 ( $p=0.01)$. This means that high priced medicines are less available. Pharmacy stores keep anti-cancer drugs from both local $(81.9 \%)$ and foreign (18.1\%) pharmaceutical companies. In order to evaluate sales performance of pharmacies in context of oncology drugs, monthly number of cancer patients buying medicines from these pharmacies has been studied as well. It has been found that supply of anti-cancer drugs by pharmaceutical companies among medicine stores is not homogenous. Availability and sales rate of oncology products in some pharmacies situated within the same area is way more than others and the number of customer (cancer patient) varies by wide margins. A comparative analysis on availability rate of model versus retail pharmacies in different areas of Dhaka city has been carried out. Retail pharmacies near cancer-care hospitals tend to keep more anti-cancer medicines compared to those situated away from cancer-care hospitals.
\end{abstract}

Keywords: Cancer, Anti-cancer drugs, Availability, Model Pharmacy, Retail Pharmacy.

\section{Introduction}

According to a World Health Organization (WHO) report, 9.6 million people died globally on 2018 due to cancer making it second highest leading cause of mortality worldwide. Moreover, the number of new cancer cases worldwide is predicted to increase to 21.4 million by the year 2030 (Soerjomataram et al., 2012). The alarming number of cancer cases indicates that an ideal cancer care health system is required for efficient management of the disease. An effective oncology care system incorporates palliative care along with anti-neoplastic therapy as soon as possible with the onset of cancer (Lagman and Walsh, 2005; Byock, 2000). Anticancer drugs make an integral part of oncology care system. Cancer-care medicines (also known as antineoplastic drugs) play a crucial role in the course of treatment of malignant diseases. These medicines can be classified into antimetabolites, alkylating agents, anthracyclines and other cytotoxic agents, anti-

Corresponding author: Nusrat Ahmed; Email: nusrat.9208@du.ac.bd

DOI: https://doi.org/10.3329/bpj.v23i1.48336 
proliferates and immuno-suppressants, antilymphocytes and monoclonal antibodies.

The World Health Organization updated its $19^{\text {th }}$ model list of essential medicines for cancer in the year 2015 (WHO, 2019). Essential medicines as defined by WHO are those that 'meet the priority health care needs of the population and are intended to be available in adequate amounts, in the appropriate dosage forms, with assured quality and adequate information, and at a price the individual and community can afford'. Shortages of therapeutic agents are taking place at an alarming rate worldwide (Gray et al., 2012; Gatesman et al., 2011), and this has subsequent impacts on treatment success of both adult and paediatric oncology patients (Becker et al., 2013).

The accessibility of a therapeutic agent depends upon a complicated series of steps (ESMO, 2016). These include registration or licensing of the medicine under proper Drug Administrative body of a country. The medicine must be manufactured or adequately imported from foreign countries for adequate supply. Proper clinical practice guidelines must be implemented and appropriate purchasing allocation should be distributed by the public health sector. The extent to which a medicine is reimbursed also influences accessibility. These factors directly impact out-of-pocket costs of a patient (ESMO, 2016; Wagenaar et al., 2014). The price of anti-cancer medicines can also act as a limiting factor for accessibility (Martei et al., 2018). Availability of an essential medicine has a direct impact on the patient's health expenditure (Havrilesky et al., 2012). This may eventually cause a delay in the start and advancement of therapy (Cheema et al., 2012). Thus, issues regarding unavailability can ultimately have adverse effects on the total cancer-care health system of a country (Becker et al., 2013).

According to a study conducted by European Society for Medical Oncology (ESMO) in 63 countries outside Europe, the major barriers to accessibility to anti-cancer medicaments were restrictive budgets and inadequate supply. Even though budgetary limitations were considered as major barrier to availability in high-income countries, deficiency of supplier was identified as a dominant barrier in low-income countries (ESMO, 2017). In Bangladesh, lack of reliable supplier was identified as presiding barrier to accessibility for anti-cancer drugs like Erlot (Lung Cancer), Afatan (Lung cancer), Crizot (Lung cancer), Paritun (Colorectal cancer), Axitin (Renal cell cancer), Ipilim (Melan), Vemuraf (Melanoma) and Enzalutamide (Prostate).

Bangladesh currently has more than 1.5 million cancer patients (Bangladesh cancer country profile, 2020). On a recent WHO report it was found that there were about 150,781 new cases in Bangladesh. The report stated that there were 85,715 male and 67,066 female cancer patients in 2018 around the country (Bangladesh-Globalcancer observatory, Globocan 2018.). Affordability and availability of cancer-care medicines can be an issue of serious concern for a lower middle-income country like Bangladesh. The health sector in Bangladesh is not completely developed owing to unorganized management of medicaments, mixing of adulterated or substandard substances to active ingredients as well as inadequate patients counselling (Mamun et al., 2016). However, the pharmaceutical sectors are emerging as one of the potential sectors of the country. Pharmaceutical stores act as a connecting pathway between the pharmaceutical companies, patients and physicians (Ahmed et al., 2009). Pharmacy stores which include retail, model and pharmacies in hospitals are the trade place of pharmaceutical products from where patients can avail medicines whenever required (Chagati, 2005).

The present study focuses on availability of anticancer drugs in these pharmacies. The study has been conducted to get an overview of the current scenario of anti-cancer drugs availability in pharmacies and variety of brand name medicines offered to end users who are the cancer patients. Since it was not possible to work with such a wide range of oncology products due to restraints on time and resources, we targeted the WHO enlisted essential anti-cancer drugs which are most commonly prescribed for our survey. Research projects on the availability of anti-cancer 
medicines have been conducted independently in many Asian countries. For example, in China, two cross-sectional surveys have been conducted in 2012 and 2016 to evaluate availability and affordability of cancer-care medicines in the country's Jiangsu Province (Zhu et al., 2019). In 2018, a study was conducted in Pakistan which gave an insight on the availability of anti-cancer drugs across the country (Sarwar et al., 2018). However, sufficient work has not been conducted in this area in Bangladesh. The results of the current study can be useful in finding out probable ways to improve total cancer-care system in the country.

The main objectives of our survey are (a) Finding out eleven most commonly prescribed WHO enlisted essential drugs for top 5 prevalent cancer types in Bangladesh. (b) Evaluation of the availability of selected medicines among the surveyed stores. (c) Identification of the top companies, both local and foreign related to the sales of anticancer drugs. (d) Establishment of a comparison between availability of anti-cancer drugs in model and retail pharmacy. (e) Finding out correlation between pricing and availability of medicament.

\section{Materials and Methods}

\section{Data sources}

Primary data source: (a) 151 Pharmaceutical stores (including 119 retail, 27 model and 5 hospital pharmacies) in Dhaka city, Bangladesh. The hospital pharmacies surveyed were Dhaka Medical College Hospital (DMCH), Bangabandhu Sheikh Mujib Medical University (BSMMU), National Institute of Cancer Research and Hospital (NICRH), City Hospital and Ibn Sina Hospital. The main areas surveyed were Shahbagh, Dhanmondi, Mohammadpur, Panthapath, Mirpur, and Dhaka Medical College area within Dhaka city. (b) The oncologists of three medical college hospitals (Dhaka Medical College Hospital (DMCH), Bangabandhu Sheikh Mujib Medical University (BSMMU) and National Institute of Cancer Research and Hospital (NICRH)).
Secondary data source: WHO Bangladesh cancer country profile 2020, WHO model list of essential medicines 2015, Essential drug list DGDA (2016), OTC medicine list DGDA (2016), research journals, related books and online sources were secondary sources of information. Collected data were analysed by using statistical packages such as IBM SPSS and Microsoft Excel for windows.

Study population, sampling and study design: We carried out an extensive literature review on existing similar studies conducted in different countries. Depending on gathered information from literature review, we sketched a plan for a wellstructured research. The next steps for this research work were (a) finding out top five prevalent cancer types in Bangladesh from previous studies, (b) identification of WHO enlisted essential medicaments for cancer, (c) selection of ten anticancer drugs to be used in this study with expert advice from oncologists, (d) determination of sample size for pharmaceutical stores and (e) data collection.

(a) Finding out top five prevalent cancer types in Bangladesh from previous studies: At first, we identified the most prevalent cancer cases in Bangladesh through a recent World Health Organization report. It is reported that among a total of 1,50, 781 new cancer cases in 2018, about 20,906 patients (13.9\%) suffer from oesophageal cancer. About 13,401 people (8.9\%) suffer from lip and oral cavity cancer; $12,764(8.5 \%)$ suffer from breast cancer; 12,374 (8.2\%) patients suffer from Lung cancer while cervix and uterus cancer is suffered by $8,068(5.4 \%)$ patients. A total of 83,268 (55.2\%) include other cases of cancer. Thus according to International Agency for Research on Cancer WHO, the top five prevalent cancer cases in Bangladesh are lung, breast, cervix, lip and mouth and oesophageal cancer.

(b) Identification of $\mathrm{WHO}$ enlisted essential medicaments for cancer: We enlisted a total of 59 antineoplastic medicines under the sub-class of cytotoxic, targeted therapies, immune-modulators, hormones and anti-hormones and supportive medicines (WHO Technical report series. Geneva: 
World Health Association 2015. The selection and use of essential medicines). We then separated out the medicaments effective in the treatment of lung, breast, cervix, lip and mouth and oesophageal cancers.

(c) Selection of anti-cancer medicines: We wanted to target the most commonly prescribed medicines among the 59 antineoplastic medicines included in the WHO list of essential medicines 2019. The anticancer medicines were identified based on the WHO essential medicine list 2019, the 2016 national essential medicine list retrieved from DGDA website, feedback from several oncologists and literature reviews.

We consulted oncologists from reputed institutions in Dhaka city namely Dhaka Medical College Hospital (DMCH), Bangabandhu Sheikh Mujib Medical University (BSMMU) and National Institution for Cancer Research and Hospital (NICRH). We took face-to-face interviews of oncologists and listed down eleven anti-cancer medicines that are commonly prescribed for five malignancies (lung, breast, cervix, lip and mouth and oesophageal) with a high morbidity and fatality rate in Bangladesh. Out of the 11 medicines surveyed, all of these were on the WHO essential medicine list and 6 were on the national essential medicine list. The eleven essential medicines sampled covered nearly Sample of questionnaire for pharmacy stores-
$18.6 \%$ of the anticancer medicines on the WHO essential medicine list.

(d) Determination of sample size for pharmaceutical stores: According to Directorate General of Drug Administration (DGDA) website, a total of 4470 allopathic retail pharmacies in Dhaka district were officially registered under DGDA by August 2019. From the list of model pharmacies retrieved from DGDA website (August 2019), we found that 77 model pharmacies were situated in Dhaka district (Panthapath, Gulshan, Banani, Mirpur, Dhanmondi, Uttara, Mohammadpur, Shahbagh, Baridhara). So, the total population of pharmaceutical stores in Dhaka district summed up to 4547 at the time of survey. We calculated the sample size for 4547 stores with the following parameters: (a) 95\% Confidence Interval and (b) $8 \%$ margin of error. We used the following equation which is predetermined for $95 \%$ Confidence Interval $-n=N / l+N(e)^{2}$ where, $\mathrm{n}$ is sample size, $\mathrm{N}$ denotes population size and $\mathrm{e}$ stands for margin of error (Morse, 2000). After calculation, we found out that a total of 151 pharmacies were to be surveyed if we wanted to be $95 \%$ sure that actual value of the responses lies within $\pm 8 \%$ of the measured / surveyed value. Thus, we surveyed a total of 151 pharmacies including 119 retail, 27 model and 5 hospital pharmacies.

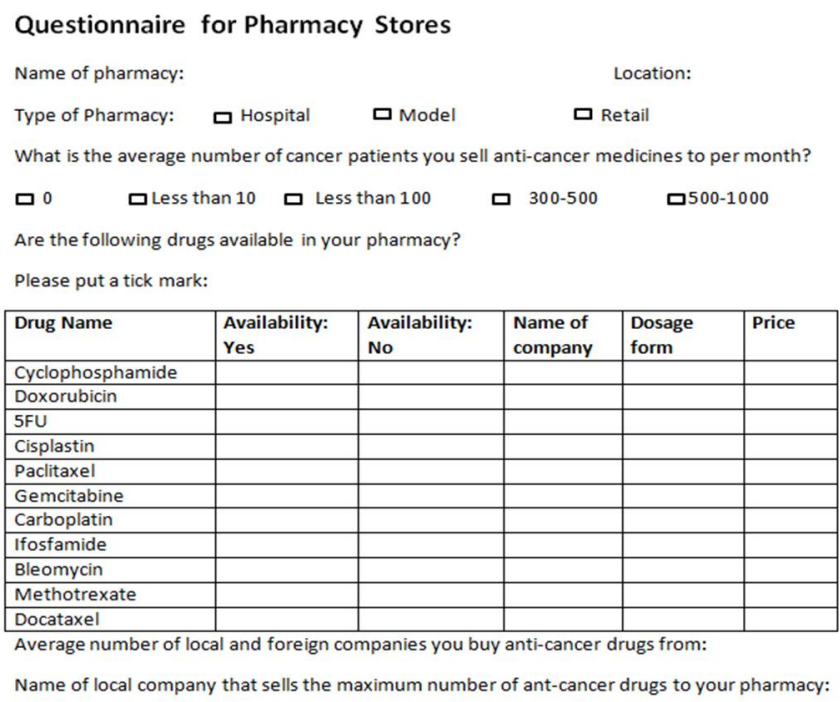


(e) Data collection: The methods of data collection were survey via semi-structured questionnaire for oncologists. We took one-on-one interviews of oncologists to get their expert advice. We then prepared a structured questionnaire for pharmacy stores that aimed to understand and analyse the availability of these drugs in various pharmacies. The most important aspects of our questionnaire were: (a) Number of anti-cancer drugs kept by each store (b) Number of local and foreign companies each pharmacy keeps anti-cancer drugs from (c) Number of patients who purchase drugs from these drug stores each month (d) What kind of pharmacy are they (retail, model or hospital) (e) Price and dosage form of the medicines.

\section{Results and Discussion}

Selected medicines that we worked with: The eleven medicines that we worked with were Doxorubicin, cyclophosphamide, Cisplatin,
5-Fluorouracil (5FU), Methotrexate, Bleomycin, Carboplatin, Paclitaxel, Docetaxel, Ifosfamide and Gemcitabine. At the time of the survey, if anti-cancer drugs were present at the pharmacy settings then they were considered as available. Among the 151 pharmacies surveyed, the most available medicines are Doxorubicin (17.9\%), Cyclophosphamide (16.6\%), Cisplatin (16.6\%), Methotrexate (16.3\%), 5FU (15.2\%), Bleomycin (13.9\%), Carboplatin (12.6\%), Paclitaxel (10.6\%) followed by Ifosfamide (12.6\%) (Figure 1). Gemcitabine (9.3\%) and Docataxel $(9.3 \%)$ were the least available drugs among the pharmacies surveyed. Accessory information such as dosage form and amount of medicine packaged for commercial purpose was availed through our survey; backed-up by online sources. Information about the top most commonly prescribed anti-cancer drugs that were found through our survey are summarised in table 1 .

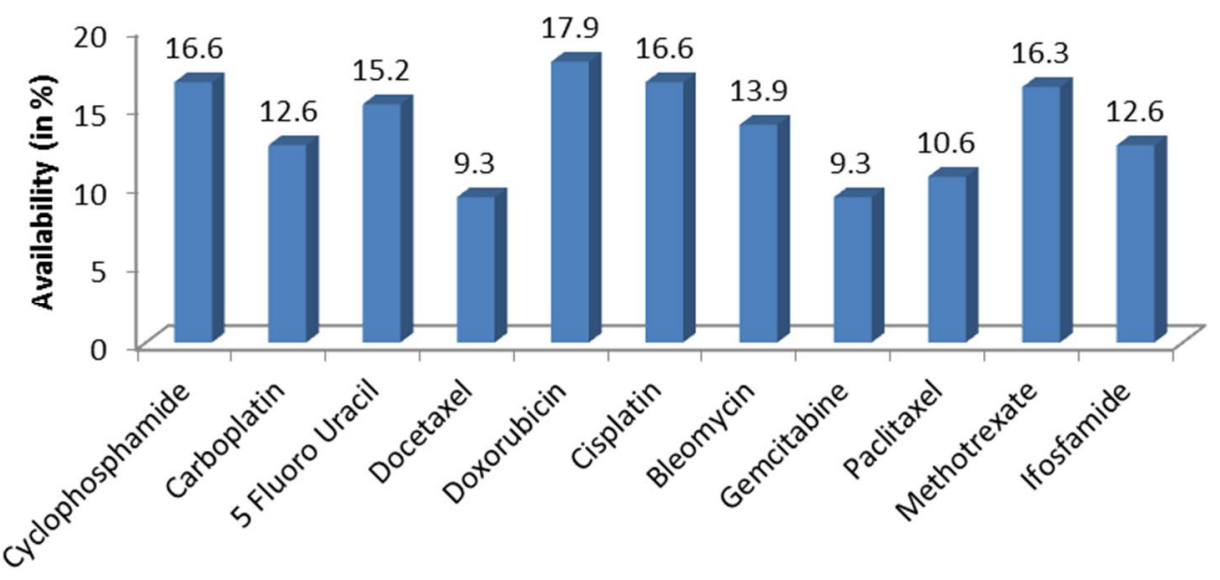

Generic name of drug

Figure 1. Percentage availability of anti-cancer medicines among pharmaceutical stores in Dhaka.

Overall availability in the medicinal stores surveyed: In $74 \%$ of all the stores surveyed there were no anti-cancer drugs at all. Around 90-100\% drugs were found in only $7 \%$ of the drug stores. $14 \%$ of the stores kept more than 6 drugs (50\%) among the eleven drugs. The drugs which are sold the most are doxorubicin, cyclophosphamide, cisplatin, carboplatin, methotrexate and 5-fluorouracil. The anti-cancer drugs available in our country are not distributed equally in drug stores across all parts of Dhaka city. The drugs are not even equally supplied by the pharmaceutical companies. One of the marketing strategies followed by companies might include supply to a narrow range of pharmaceutical 
stores for sales of anti-cancer medicines. Greater number of cancer patients is expected to visit drug stores situated near cancer-care hospitals. Thus drug supply by companies to medicine stores is especially dense in areas close to the hospitals providing oncological treatment. Again in some of the pharmacies near cancer-care hospitals, varieties and supply of drugs is way more than the others. For example, $7 \%$ medicine stores had access to almost all types of oncological products supplied by leading companies. But the same type of supply is not available in majority of pharmacies situated both close to and far away from cancer hospitals. Lower availability of oncology products in pharmacies away from cancer-care hospitals may become problematic for patients living far away from oncology hospitals. This means that they have to travel long distances before availing prescribed medicaments even at times of emergencies.

Table 1. List of eleven essential anti-cancer medicines surveyed in Dhaka city.

\begin{tabular}{|c|c|c|c|c|c|c|}
\hline Generic medicine & $\begin{array}{l}\text { Essential } \\
\text { medicine } \\
\text { list WHO }\end{array}$ & $\begin{array}{l}\text { Essential } \\
\text { medicine } \\
\text { list DGDA }\end{array}$ & $\begin{array}{l}\text { Commonly } \\
\text { prescribed }\end{array}$ & $\begin{array}{l}\text { Dosage } \\
\text { form }\end{array}$ & Amount & Main indication \\
\hline Cyclophosphamide & Yes & Yes & Yes & $\begin{array}{l}\text { Vial } \\
\text { Tablet }\end{array}$ & $\begin{array}{l}500 \mathrm{mg} \\
50 \mathrm{mg}\end{array}$ & Breast Cancer \\
\hline Cisplatin & Yes & Yes & Yes & Injection & $50 \mathrm{mg} / 50 \mathrm{ml}$ & $\begin{array}{l}\text { Cervical, Lung, Oral, } \\
\text { Esophageal Cancer }\end{array}$ \\
\hline Carboplatin & Yes & No & Yes & Injection & $50 \mathrm{mg} / 5 \mathrm{ml}$ & $\begin{array}{l}\text { Breast, Cervical, Lung, } \\
\text { Oral, Esophageal } \\
\text { Cancer }\end{array}$ \\
\hline 5-Fluorouracil & Yes & Yes & Yes & $\begin{array}{l}5 \mathrm{ml} \\
\text { Ampoule }\end{array}$ & $50 \mathrm{mg} / \mathrm{ml}$ & $\begin{array}{l}\text { Breast, Oral, } \\
\text { Esophageal Cancer }\end{array}$ \\
\hline Bleomycin & Yes & Yes & Yes & Vial & $15 \mathrm{mg}$ & Cervical Cancer \\
\hline Docetaxel & Yes & No & Yes & Injection & $20 \mathrm{mg} / \mathrm{ml}$ & Breast Cancer \\
\hline Doxorubicin & Yes & Yes & Yes & Vial & $\begin{array}{l}10 \mathrm{mg} \\
50 \mathrm{mg} \text { in } \mathrm{HCl}\end{array}$ & Breast Cancer \\
\hline Paclitaxel & Yes & No & Yes & Injection & $6 \mathrm{mg} / \mathrm{ml}$ & $\begin{array}{l}\text { Breast, Cervical, Lung, } \\
\text { Oral Cancer }\end{array}$ \\
\hline Methotrexate & Yes & Yes & Yes & $\begin{array}{l}\text { Vial } \\
\text { Tablet }\end{array}$ & $\begin{array}{l}50 \mathrm{mg} \\
2.5 \mathrm{mg}\end{array}$ & Breast Cancer \\
\hline Gemcitabine & Yes & No & Yes & Vial & $\begin{array}{l}200 \mathrm{mg} \\
1 \mathrm{~g}\end{array}$ & $\begin{array}{l}\text { Lung, Oral, } \\
\text { Esophageal Cancer }\end{array}$ \\
\hline Ifosfamide & Yes & No & Yes & Vial & $\begin{array}{l}1 \mathrm{~g} \\
2 \mathrm{~g}\end{array}$ & Cervical Cancer \\
\hline
\end{tabular}

Range of brand name products offered to cancer patients: To understand whether a reasonable range of companies offered anti-cancer drugs or not we aimed to find number of companies each pharmacy keeps. About $75 \%$ stores kept no drugs at all. Only $1.1 \%$ of the stores had a maximum range of 5 companies for some of the drugs. About $23.2 \%$ of all pharmaceutical stores surveyed keep drugs from
Beacon pharmaceuticals. The drugs supplied to them are mostly by Beacon Pharmaceuticals Ltd. A total of 51 generic anti-neoplastic drugs are reported to be manufactured by this company, which is considered to be the leading local manufacturer for oncology products in Bangladesh. Beacon Pharmaceuticals Ltd. is the leading company for cancer drugs followed by Drug International Ltd. (7.95\%), Healthcare 
Pharmaceuticals Ltd. (6.62\%), Techno Drugs Ltd. (5.29\%), Incepta Pharmaceuticals Ltd. (2.65\%), ACI Limited (1.32\%) and Delta Pharma Ltd. (0.67\%). Very few pharmacies kept drugs from international companies such as Sandoz (A Novartis Version) (2.64\%), Novartis (Bangladesh) Ltd. (1.99\%), Julphar Bangladesh Ltd. (1.32\%), and Jus-Pharma
$(0.67 \%)$. Around $81.9 \%$ stores kept only local company drugs and only $18.1 \%$ kept international drugs. Overall availability of anti-cancer medicines from local companies (Beacon, Drug International, Healthcare, Techno, Incepta) is more than foreign companies (Sandoz, Novartis, Jus and Julphar) (table 2).

Table 2. Percentage availability of anti-cancer drugs from different local and foreign companies.

\begin{tabular}{llc}
\hline $\begin{array}{l}\text { Type of } \\
\text { company }\end{array}$ & Name of the company & $\begin{array}{c}\text { \% Pharmaceutical stores that keep anti- } \\
\text { cancer drugs from the company }\end{array}$ \\
\hline Local companies & Beacon Pharmaceuticals Ltd. & $23.2 \%$ \\
& $\begin{array}{l}\text { Drug International Ltd. } \\
\text { Healthcare Pharmaceuticals }\end{array}$ & $7.95 \%$ \\
& Ltd. & $6.62 \%$ \\
& Techno Drugs Ltd. & $5.29 \%$ \\
& Incepta Pharmaceuticals Ltd. & $2.65 \%$ \\
& ACI Limited & $1.32 \%$ \\
Foreign & Delta Pharma Ltd. & $0.67 \%$ \\
companies & Sandoz (A Novartis Version) & $2.64 \%$ \\
& Novartis (Bangladesh) Ltd. & $1.99 \%$ \\
& Julphar Bangladesh Ltd. & $1.32 \%$ \\
& Jus-Pharma & $0.67 \%$ \\
\hline
\end{tabular}

Sales performance of pharmaceutical stores in context of anti-cancer drugs: All the eleven essential medicines are prescription drugs since these are not included in the OTC list of medicines (2016) retrieved from DGDA. We wanted to find out the sales performance of the pharmacies in case of these eleven anti-cancer drugs. To analyse this aspect, we asked about the number of patients who purchase anti-cancer drugs from each pharmacy per month. Among 151 medicine stores, only $4.5 \%$ of the stores sold anti-cancer drugs to 500-1000 patients per month whereas $5.4 \%$ sold to $300-500$ patients. About $16.1 \%$ of the drug stores sold to less than 100 patients per month. Other $74 \%$ of the pharmacies sold medicines to no cancer patient at all. Sales rate among pharmacies that keep anti-cancer drugs is not homogenous. Number of customer (cancer patient) varies by wide margins. The small number of drug stores selling oncology medicines to a maximum of
600-1000 patients per month, offer a wide range of oncology medicines. We found $90-100 \%$ availability of the eleven anti-cancer drugs in these stores.

Correlation of availability and price: The price of oncology medicines accounts for about one-fourth of all cancer treatment costs, which have increased ten times in the last decade (Kolasani, 2016). In Bangladesh, there is a shortage of medicine supply in public facilities (Kasonde et al., 2019). As a result, many patients (93\% in 2014) purchase their medicines out-of-pocket (Bangladesh health system review, 2015). Previous studies show that cost of medicine largely contributes to availability in the healthcare settings in Low and Middle Income Countries (LMICs) (Kelly, 2014).

In order to evaluate whether there is any correlation between price of medicament and availability, price information was collected from retailers. For each generic medicine, Maximum 
Retail Price of two leading brand name drugs were collected. Average of the two prices was calculated and a scatter plot for availability (in \%) and price (in Bangladeshi Taka) was generated using Microsoft Excel. The price of each strip or vial is found for the largest amount (in milligram) of drug commercially available. The average prices found for per strip or per vial of each generic medicine are: Cyclophosphamide (BDT 700), Carboplatin (BDT 3800), Doxorubicin (BDT 950), Cisplatin (BDT 815), Methotrexate (BDT 450), 5 Fluorouracil (BDT 100), Bleomycin (BDT 1500), Paclitaxel (BDT 9900),
Ifosfamide (BDT 2180), Gemcitabine (BDT 5000) and Docataxel (BDT 3500).The Pearson's correlation coefficient, $r$ is calculated using IBM SPSS. There is a significant negative relationship between price and availability of oncology medicine for which Pearson's correlation co-efficient ' $r$ ' is found to be $0.739(\mathrm{p}=0.01)$. This means that high priced medicines are less available (Figure 2). Since we worked with eleven medicines $(n=11)$, the number of degree of freedom is $9(\mathrm{n}-2)$. The relationship is significant as the p-value for the calculated coefficient is $0.01(\mathrm{p} \leq 0.05)$ (table 3$)$.

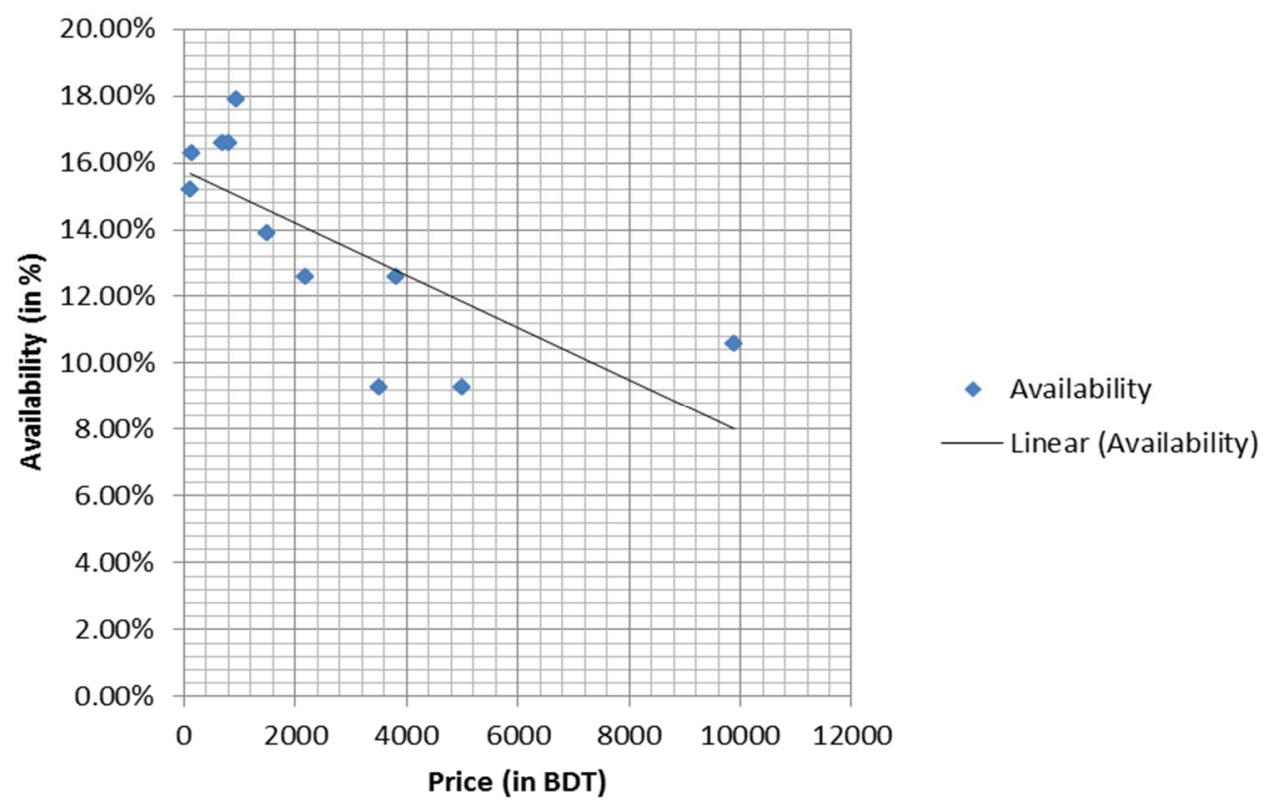

Figure 2. Scatter plot showing correlation between availability and price.

Table 3. Correlation of price and availability of anti-cancer medicines.

\begin{tabular}{|c|c|c|c|}
\hline \multicolumn{4}{|l|}{ Correlations } \\
\hline & & $\begin{array}{l}\text { Price of medicine } \\
\text { (in BDT) }\end{array}$ & $\begin{array}{c}\text { Availability } \\
\text { (in \%) }\end{array}$ \\
\hline \multirow{3}{*}{$\begin{array}{l}\text { Price of medicine } \\
\text { (in BDT) }\end{array}$} & Pearson Correlation & 1 & $-0.739^{* *}$ \\
\hline & Sig. (2-tailed) & & 0.009 \\
\hline & $\mathrm{N}$ & 11 & 11 \\
\hline \multirow{3}{*}{ Availability (in \%) } & Pearson Correlation & $-0.739^{* *}$ & 1 \\
\hline & Sig. (2-tailed) & 0.009 & \\
\hline & $\mathrm{N}$ & 11 & 11 \\
\hline
\end{tabular}


Comparison of availability in retail versus model pharmacies: Retail pharmacies in Mohammadur, Dhanmondi, Panthapath and Mirpur areas (where density of cancer care hospitals is low) keep almost no anti-cancer drugs at all. In these areas, model pharmacies contain $80-90 \%$ of the eleven anti-cancer drugs if not all the essential oncology medicines. However a considerable amount (20\%) of retail pharmacies in DMCH and BSMMU areas were found to contain cancer-care medicines (Figure 3). Some medicine stores near Dhaka Medical College Hospital, namely Jhorna, Maa, Ms. Lily, Jaman Pharmacies have almost all of the anti-cancer drugs (90-100\%). Among the model pharmacies, Lazz Pharma and AKS pharmacy have enough supply (75-
$80 \%$ ) of drugs for cancer patients. As in case of the pharmacies near BSMMU, pharmaceutical stores like Naz, Bhai Bhai, A to Z, Kazi, VIP, United Drug, Doyal, Alif and Ovi keep 90-100\% of the eleven anticancer drugs. Majority of the pharmacies near NICRH are retail pharmacies and they all have almost all the drugs required for a cancer patient receiving treatment from there. Pharmaceutical stores near Square hospital namely Lazz pharma and Tazrin Pharmacy have sufficient amount (75-85\%) of anticancer drugs. In areas such as Dhanmondi, Mohammadpur and Mirpur, only Lazz Pharma is found to have (55-65\%) of the anti-cancer drugs. The main findings of our survey is summarised in Table 4.

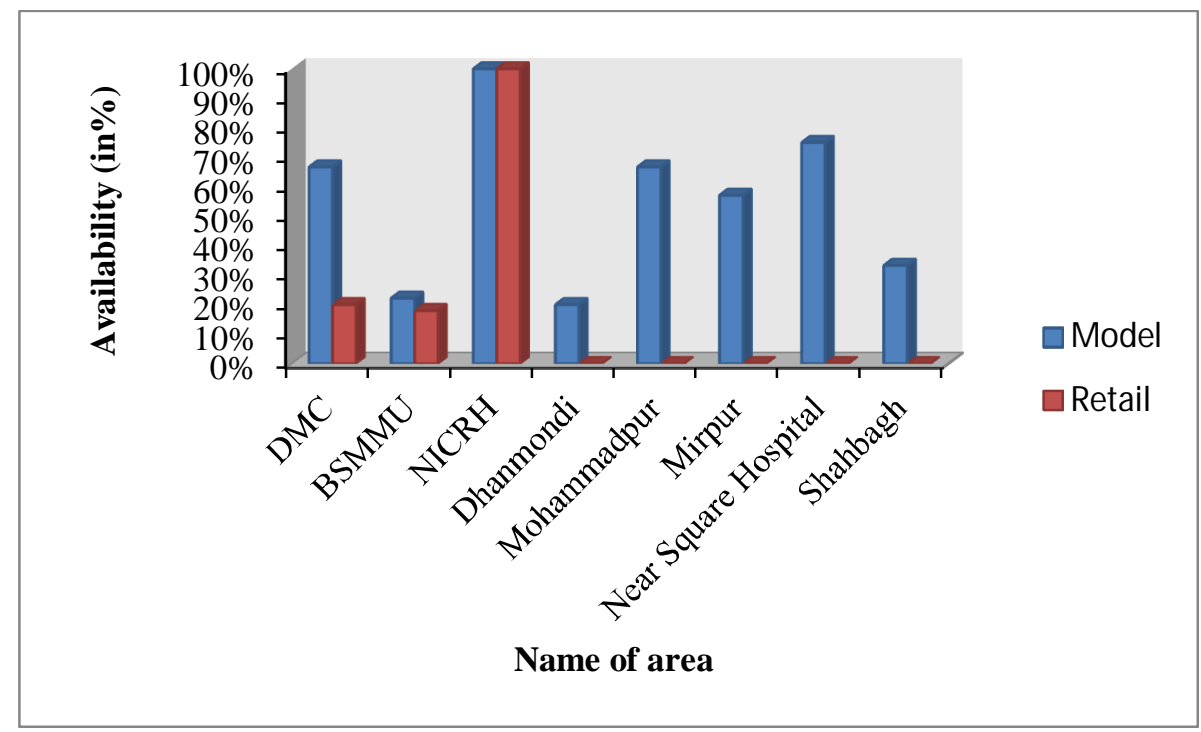

Figure 3. Availability in model versus retail pharmacies among various areas in Dhaka.

Table 4. Availability status of anti-cancer medicines among pharmaceutical store.

\begin{tabular}{lc}
\hline Parameters & $\begin{array}{c}\text { \% Pharmacy } \\
\text { stores }\end{array}$ \\
\hline Availability of Anti-cancer drugs among study population: & \\
\hline A. Available & $25.9 \%$ \\
B. Not Available & $74.1 \%$ \\
\hline Percentage of anti-cancer drugs kept by each store: & \\
\hline A. $0 \%$ & $74.1 \%$ \\
B. $10-30 \%$ & $4.5 \%$ \\
C. $30-50 \%$ & $7.1 \%$ \\
D. $50-80 \%$ & $7.1 \%$ \\
E. $90-100 \%$ & $7.1 \%$ \\
\hline
\end{tabular}


Number of companies that each store keeps anti-cancer drugs from:

\begin{tabular}{llc}
\hline A. & 0 & $74.1 \%$ \\
B. & 1 & $15.1 \%$ \\
C. & 2 & $4.1 \%$ \\
D. & 3 & $2.2 \%$ \\
E. & 4 & $3.4 \%$ \\
F. & 5 & $1.1 \%$ \\
\hline
\end{tabular}

Number of patients who purchase anti-cancer drugs from each pharmacy per month:

\begin{tabular}{|c|c|}
\hline A. 0 & $74.1 \%$ \\
\hline B. $>10$ & $9.8 \%$ \\
\hline C. $>100$ & $6.3 \%$ \\
\hline D. $300-500$ & $5.4 \%$ \\
\hline E. $500-1000$ & $4.5 \%$ \\
\hline \multicolumn{2}{|c|}{ Availability of anti-cancer drugs from various companies among pharmacies : } \\
\hline A. Beacon Pharmaceuticals Ltd. & $23.2 \%$ \\
\hline B. Drug International Ltd. & $7.95 \%$ \\
\hline C. Healthcare Pharmaceuticals Ltd. & $6.62 \%$ \\
\hline D. Techno Drugs Ltd. & $5.29 \%$ \\
\hline E. Incepta Pharmaceuticals Ltd. & $2.65 \%$ \\
\hline F. Sandoz (A Novartis Version) & $2.64 \%$ \\
\hline G. Novartis (Bangladesh) Ltd. & $1.99 \%$ \\
\hline H. ACI Limited & $1.32 \%$ \\
\hline I. Julphar Bangladesh Ltd. & $1.32 \%$ \\
\hline J. Jus-Pharma & $0.67 \%$ \\
\hline K. Delta Pharma Ltd. & $0.67 \%$ \\
\hline \multicolumn{2}{|c|}{ Availability of each anti-cancer drug among all pharmaceutical stores surveyed: } \\
\hline A. Cyclophosphamide & $16.6 \%$ \\
\hline B. Carboplatin & $12.6 \%$ \\
\hline C. 5-Fluorouracil & $15.2 \%$ \\
\hline D. Docetaxel & $9.3 \%$ \\
\hline E. Doxorubicin & $17.9 \%$ \\
\hline F. Cisplatin & $16.6 \%$ \\
\hline G. Bleomycin & $13.9 \%$ \\
\hline H. Gemcitabine & $9.3 \%$ \\
\hline I. Methotrexate & $16.3 \%$ \\
\hline J. Paclitaxel & $10.6 \%$ \\
\hline \multicolumn{2}{|c|}{ Percentage of pharmacies keeping ant-cancer drugs from local or foreign companies: } \\
\hline A. Local Companies & $81.9 \%$ \\
\hline B. Foreign Companies & $18.1 \%$ \\
\hline
\end{tabular}

\section{Recommendations}

Availability of medicines plays a significant role in the course of treatment of a patient. Cancer has a high morbidity rate among non-communicable lethal diseases. Thus, proper supply and availability of essential oncology products must be ensured by government and regulatory bodies. After conducting the proposed research and going through WHO Technical report on pricing of cancer medicines and 
its impacts (2019), the following recommendations can be taken under consideration:

- Lack of wide range of local companies that offer anti-cancer products may impose price related barriers to availability. Inclusion of more number of generic medicine competitors is necessary to reduce pricing of medicaments.

- There is a significant difference between availability of anti-cancer medicines from leading pharmaceutical company (market leader) and its competitors in context of oncology products. Market competitors should come-up with effective market policies to increase their sales rate. In this way, patients (customers) may avert the risks of excessive pricing set by monopoly business leader.

- Availability in areas far from cancer care hospitals need to be increased. In this way, patients living far away from these hospitals can avail medicines whenever required.

- Lack of supply compared to required amount may have direct impact on availability. Supply by pharmaceutical companies must be increased.

- High priced medicines are less available. Thus, regulatory bodies must account for appropriate pricing policies at the national level to increase overall availability and accessibility.

- Unequal distribution of oncology products by pharmaceutical companies among retailers within the same area has been identified. Imbalanced sales rate of pharmacy stores located within the same area may increase chances of developing improper pricing policy by middleman (retailers). Thus, distribution by companies needs to be homogenous.

\section{Conclusions}

This is a preliminary study of commonly prescribed medicines for only five of the most occurring cancer types in Bangladesh conducted in some selected pharmaceutical stores in Dhaka. We recommend further study with greater sample size of medicine stores. However, several problems regarding availability of oncology medicines have been identified through our research project. The result of our study can be useful to determine these problematic areas making cancer treatment in Bangladesh more idealistic. Official regulatory authorities of our country should take necessary measures and formulate appropriate policies to ensure adequate availability of cancer medicines. In this way, the end users of oncology medicines (cancer patients) will be benefitted and a better healthcare system will be ensured in Bangladesh.

\section{References}

Ahmed, S.M., Hossain, M.A. and Chowdhury, M.R. 2009. Informal sector providers in Bangladesh: how equipped are they to provide rational health care? Health Pol. Planning. 24, 467-478.

Sarwar, M.R., Iftikhar, S. and Saqib, A. 2018. Availability of anticancer medicines in public and private sectors, and their affordability by low, middle and highincome class patients in Pakistan. BMC Cancer. 18, 1-11.

Bangladesh cancer country profile. 2020. The article was retrieved from https:// www .who.int/cancer/countryprofiles/BGD_2020.pdf

Bangladesh-Globalcancer observatory, Globocan 2018. The article was retrieved from https://gco.iarc.fr/ today/data /factsheets/populations/50-bangladesh-factsheets.pdf.

Bangladesh health system review. 2015. Health System Trans. 5, 55-60. This article was retrieved from: http://www.wpro.who.int/asia_pacific_observatory/hit s/series/bgd_health_system_review.pdf

Becker, D.J., Talwar, S., Levy, B.P., Thorn, M., Roitman, J., Blum, R.H., Harrison, L.B. and Grossbard, M.L. 2013. Impact of oncology drug shortages on patient therapy: Unplanned treatment changes. J. Oncol. Pract. 9, e122-e128.

Byock, I. 2000. Completing the continuum of cancer care: integrating life-prolongation and palliation. $C A: A$ Cancer J. Clinicians. 50, 123-132.

Chaganti, S.R. 2005. Pharmaceutical Markeing in India, $1^{\text {st }}$ edition, pp. 175-178.

Cheema, P.K., Gavura, S., Migus, M., Godman, B., Yeung, L. and Trudeau, M.E. 2012. International variability in the reimbursement of cancer drugs by publically funded drug programs. Curr. Oncology. 19, e165e176. 
Cherny, N., Sullivan, R., Torode, J., Saar, M., and Eniu, A. 2016. ESMO European Consortium study on the availability, out-of-pocket costs and accessibility of antineoplastic medicines in Europe. Ann. Oncology, 27, 1423-1443.

Essental-drug-list-DGDA. 2016. This article was retreived from https://www.dgda. gov.bd /index.php/2013-0331-05-16-29/guidance-documents/219-essential-druglist-2016

Gatesman, M.L. and Smith, T.J. 2011. The shortage of essential chemotherapy drugs in the United States. $N$. Engl. J. Med. 365, 1653-1655.

Gray, A. and Manasse, H.R. Jr. 2012. Shortages of medicines: A complex global challenge. Bull. World Health Organ. 90, 158.

Havrilesky, L.J., Garfield, C.F., Barnett, J.C. and Cohn, D.E. 2012. Economic impact of paclitaxel shortage in patients with newly diagnosed ovarian cancer. Gynecol. Oncol. 125, 631-634.

Kelly, R.J. and Smith, T.J. 2014. Delivering maximum clinical benefit at an affordable price: Engaging stakeholders in cancer care. Lancet Oncol. 15, e112e118.

Kolasani, B.P., Malathi, D.C. and Ponnaluri, R.R. 2016. Variation of cost among anti-cancer drugs available in Indian market. J. Clin. Diagn. Res. 10, FC17-FC20.

Kasonde, L., Tordrup, D., Naheed, A., Zeng, W., Ahmed, S. and Babar, Z. 2019. Evaluating medicine prices, availability and affordability in Bangladesh using World Health Organisation and Health Action International methodology. BMC Health Serv. Res. 19, 383.

Lagman, R. and Walsh, D. 2005. Integration of palliative medicine into comprehensive cancer care. Sem. Oncol. 32, 134-138.

List of allopathic retail pharmacies. 2016. The article was retrieved from https://www.dgda. gov.bd/ index. php/pharmacies/allopathy-retail-pharmacy-view.

List of model pharmacies. 2019. The article was retrieved from http:// www.dgda.gov.bd/index. php/pharmacies/ whole-sale-pharmacy-view-2/319-list-of-modelpharmacy.

Mamun, M. E., Saha, T. and Islam, M. 2016. Initiation and maintenance of diseases and diagnostic database for Bangladeshi individuals. American J. Pharm. Health Res. 4, 30-42.
Martei, Y.M., Chiyapo, S., Grover, S. Hanna, C., DrydenPeterson, S., Pusoentsi, M., Shulman, L.N. and Tapela, N. 2018. Methodology to forecast volume and cost of cancer drugs in low and middle-income countries. J. Glob. Oncol. 4, 1-8.

Morse, J.M. 2000. Determining sample size. Qualitative Health Res. 10, 3-5.

Over-the-Counter (OTC) drugs list - DGDA. 2016. This article was retrieved from https://www.dgda.gov.bd/ index.php/2013-03-31-05-16-29/guidancedocuments/220-over-the-counter-otc-drugs-list.

Soerjomataram, I., Lortet-Tieulent, J., Parkin, D.M., Ferlay, J., Mathers, C., Forman, D. and Bray, F. 2012. Global burden of cancer in 2008: a systematic analysis of disability-adjusted life-years in 12 world regions. Lancet. 380, 1840-1850.

Special article ESMO International Consortium study on the availability, out-of-pocket costs and accessibility of antineoplastic medicines in countries outside of Europe. 2017. This article was retrieved from https://doi.org/10.1093/annonc/mdx521.

Wagenaar, B.H., Gimbel, S., Hoek, R., Pfeiffer, J., Michel, C., Cuembelo, F., Quesmbo, T., Afonso, P., Gloyd, S. and Sherr, K. 2014. Stock-outs of essential health products in Mozambique - longitudinal analyses from 2011 to 2013. Trop. Med. Int. Health. 19, 791-801.

WHO Technical report on pricing of cancer medicines and its impacts. 2019. This article was retrieved from https://www.who.int/medicines/areas/access/reporton-the-pricing-of-cancer-medicines.pdf?ua $=1$.

World Health Organization (WHO). 2019. World Health Organization model list of essential medicines. Mental and Holistic Health: Some International Perspectives, 119-134.

World Health Organization Technical report series. Geneva: World Health Association 2015. The selection and use of essential medicines. This article was retrieved from http://apps.who.int/iris/bitstream/ 10665/189763/189761/9789241209946_eng.pdf?ua $1 / 49$ 789241209941.

Zhu, Y., Wang, Y., Sun, X. and Li, X. 2019. Availability, price and affordability of anticancer medicines: evidence from two cross-sectional surveys in the Jiangsu Province, China. Int. J. Environ. Res. Public Health. 16, 3728. 